\title{
Peer-Facilitated Patient Education An underutilised resource
}

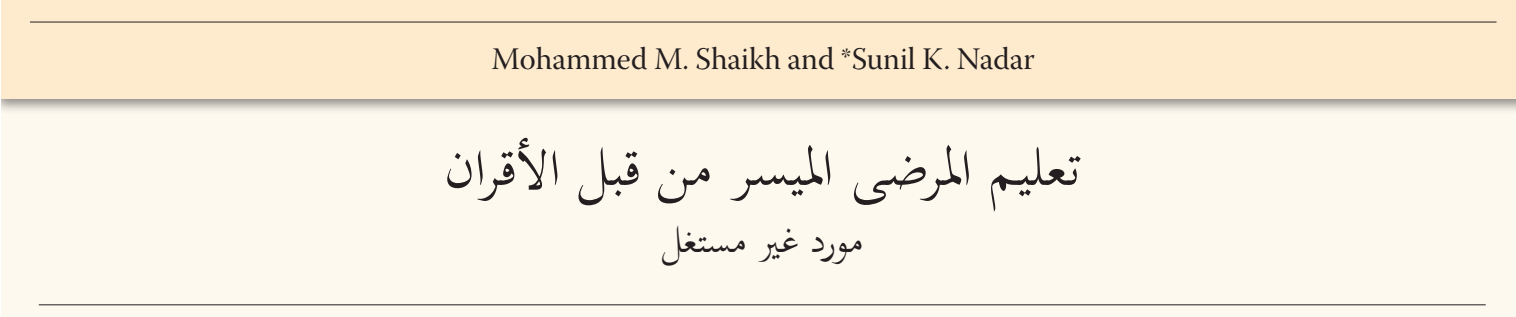

محمد شيخ و سونيل نادار

$\mathrm{P}$ EER LEARNING IS A TYPE OF LEARNING process whereby non-professional teachers of similar backgrounds and education levels learn from each other. ${ }^{1}$ Peer-assisted learning has been demonstrated to be effective in many disciplines, including among university and elementary school students. ${ }^{2,3}$ In terms of patient care, peer-led support groups allow patients or their caregivers to meet and discuss various problems and issues. Such support groups are often very popular, with participants reporting them to be extremely useful as they provide the opportunity to meet people with similar conditions and learn from each other's experiences. ${ }^{4}$

In addition, peer learning is increasingly being used as a tool for patient education. ${ }^{5}$ It has been shown to improve learning outcomes, with positive implications for clinical practice. ${ }^{6}$ Peer education programmes for patients with diseases or those undergoing certain procedures aim to improve awareness and knowledge regarding management of the disease or details of the scheduled procedure, while also providing the patients with much needed social support. $^{4-7}$ Such programmes have been shown to have a positive impact by reducing overuse of health services and increasing patients' trust in the primary and hospital care system, as reflected by a reduction in the number of health centre visits and admissions. ${ }^{8,9}$

In this issue of SQUMJ, Habibzadeh et al. studied the effects of peer-facilitated, video-based and combined peer-and-video education interventions on anxiety among patients undergoing coronary angiography. ${ }^{10}$ Indeed, as coronary angiography is an invasive procedure involving catheterisation of the heart, most patients are understandably anxious; unfortunately, this anxiety can translate into poor outcomes. ${ }^{11}$ Habibzadeh et al. found that any form of intervention significantly reduced anxiety, with no statistical difference between the various approaches used. ${ }^{10}$ These results could be due to the relatively small sample size in the study, especially as all three counselling methods are well-established. In addition, it can also be argued that both the video and peer education interventions involved similar methods, as educational videos explaining certain procedures are sometimes filmed with the aid of non-medical professionals. Despite the fact that there was no advantage to one educational approach over the others, the study nonetheless emphasises the role of peer-led education groups. ${ }^{10}$

In general, patients appear to relate better to others who have undergone the procedure themselves and may feel more comfortable asking them certain questions that they would otherwise feel embarrassed to ask a medical professional. ${ }^{7}$ However, it should be noted that peer-led education interventions should be supervised by a medical professional. Previous research among students has indicated that the presence of a senior person in authority was preferred by participants in case their peers did not know the answers and in order to ensure that the correct information was imparted. ${ }^{12}$ Despite this, peer-facilitated groups still have a useful role in supplementing the work done by often overstretched medical and nursing teams. ${ }^{5}$

Debussche et al. have published some useful suggestions for creating a successful peer-led educational experience. ${ }^{9}$ The content of such activities should be carefully created by medical personnel and use simple language written by peers without overly complicated medical jargon. The amount of information imparted should be adequate without being overwhelming. ${ }^{\text {In }}$ addition, the programme should contain elements or examples derived from the peers' own previous experiences, as this can help patients who are new to the procedure or disease to relate to the information on a more personal level. ${ }^{9}$ 
In their study, Habibzadeh et al. also demonstrated the importance of visual aids in patient education, for example in the form of a video explanation of the upcoming procedure. ${ }^{10}$ This has been previously shown to be useful for other procedures such as colonoscopies and colposcopies. ${ }^{13,14}$ As with peerfacilitated educational activities, such videos or visual aids should be made with the involvement of patients, so that the language remains simple and the content refers to real-life and relatable experiences. In effect, these videos can act as a form of peer-supported learning in their own right.

Despite evidence that peer-led patient education is helpful, this approach is still not optimally used..$^{15}$ There may be many reasons for this, including a lack of time and initiative among busy medical personnel to train patient educators. In addition, the patient educators themselves need to be motivated enough to attend peer-led events without financial incentive, as such activities are usually coordinated on a voluntary basis, although some institutions do provide some form of payment. ${ }^{15}$ Furthermore, certain patients may feel reluctant to share their experiences or knowledge with other patients as they feel they are not adequately qualified to take on this role. Others may question the medicolegal issues involved with allowing individuals without medical qualifications to provide information about various diseases and procedures. ${ }^{14}$ There is also concern that patients may discuss material that they have retrieved from the Internet from inaccurate sources. However, most of these issues can be resolved by educating medical personnel on the benefits of peer education and making sure that the contents of peerled activities are checked by medical personnel prior to delivery.

In conclusion, peer-led patient education has an important role in healthcare delivery. It creates an important bridge between patients and medical professionals and provides social support for the former by helping to alleviate procedure- or diseaserelated anxiety. One could argue that, despite continuous advancements in technology and medical care and the increasing availability of information online, there is still no replacement for traditional human contact.

\section{References}

1. Topping KJ. The effectiveness of peer tutoring in further and higher education: A typology and review of the literature. Higher Education 1996; 32:321-45. doi: 10.1007/BF00138870.

2. Field M, Burke JM, McAllister D, Lloyd DM. Peer-assisted learning: A novel approach to clinical skills learning for medical students. Med Educ 2007; 41:411-18. doi: 10.1111/j.13652929.2007.02713.x

3. Rohrbeck CA, Ginsburg Block MD, Fantuzzo JW, Miller TR. Peer-assisted learning interventions with elementary school students: A meta-analytic review. J Educ Psychol 2003; 95:2405. 2003. doi: 10.1037/0022-0663.95.2.240.

4. Dennis CL. The effect of peer support on postpartum depression: A pilot randomized controlled trial. Can J Psychiatry 2003; 48:115-24. doi: 10.1177/070674370304800209.

5. Dennis CL. Peer support within a health care context: A concept analysis. Int J Nurs Stud 2003; 40:321-32. doi: 10.1016/ S0020-7489(02)00092-5.

6. Kronish IM, Goldfinger JZ, Negron R, Fei K, Tuhrim S, Arniella G, et al. Effect of peer education on stroke prevention: The prevent recurrence of all inner-city strokes through education randomized controlled trial. Stroke 2014; 45:3330-6. doi: 10.11 61/STROKEAHA.114.006623.

7. Matthias MS, Kukla M, McGuire AB, Bair MJ. How do patients with chronic pain benefit from a peer-supported pain selfmanagement intervention? A qualitative investigation. Pain Med 2016; 17:2247-55. doi: 10.1093/pm/pnw138.

8. Danet A, Rodríguez MÁ, Peña FG, Doblas ML, Martín NL, Cerdà JC. Chronicity and use of health services: Peer education of the School of Patients. Rev Esc Enferm USP 2017; 51:e03280. doi: 10.1590/S1980-220X2017004203280.

9. Debussche X, Besançon S, Balcou-Debussche M, Ferdynus C, Delisle H, Huiart L, et al. Structured peer-led diabetes selfmanagement and support in a low-income country: The ST2EP randomised controlled trial in Mali. PLoS One 2018; 13:e0191262. doi: 10.1371/journal.pone.0191262.

10. Habibzadeh H, Milan ZD, Radfar M, Alilu L, Cund A. Effects of peer-facilitated, video-based and combined peer-and-video education on anxiety among patients undergoing coronary angiography: Randomised controlled trial. Sultan Qaboos Univ Med J 2018; 18:e61-7. doi: 10.18295/squmj.2018.18.01.010.

11. Delewi R, Vlastra W, Rohling WJ, Wagenaar TC, Zwemstra M, Meesterman MG, et al. Anxiety levels of patients undergoing coronary procedures in the catheterization laboratory. Int J Cardiol 2017; 228:926-30. doi: 10.1016/j.ijcard.2016.11.043.

12. Dehghani MR, Amini M, Kojuri J, Nabeiei P. Evaluation of the efficacy of peer-learning method in nutrition students of Shiraz University of Medical Sciences. J Adv Med Educ Prof 2014; 2:71-6.

13. Hayat U, Lee PJ, Lopez R, Vargo JJ, Rizk MK. Online educational video improves bowel preparation and reduces the need for repeat colonoscopy within three years. Am J Med 2016; 129:1219.e1-9. doi: 10.1016/j.amjmed.2016.06.011.

14. Ketelaars PJ, Buskes MH, Bosgraaf RP, van Hamont D, Prins JB, Massuger LF, et al. The effect of video information on anxiety levels in women attending colposcopy: A randomized controlled trial. Acta Oncol 2017; 56:1728-33. doi: 10.1080/ 0284186X.2017.1355108.

15. Matthias MS, Kukla M, McGuire AB, Damush TM, Gill N, Bair MJ. Facilitators and barriers to participation in a peer support intervention for veterans with chronic pain. Clin J Pain 2016; 32:534-40. doi: 10.1097/AJP.0000000000000297. 